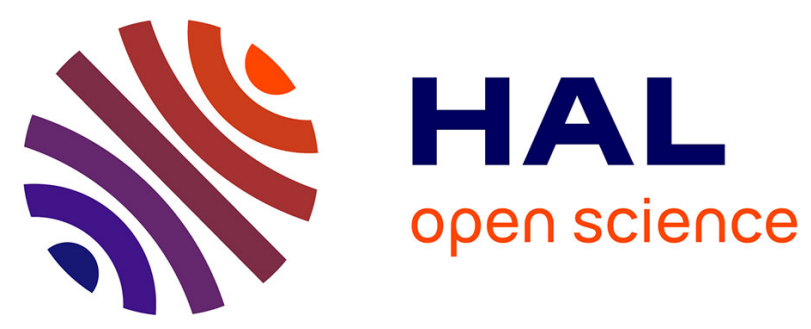

\title{
MODELLING OF DYNAMIC TENSION TESTS APPLIED TO DUCTILITY PROBLEMS
}

C. Dumont, Christophe Levaillant, Mayeul Arminjon, J. Chenot

\section{To cite this version:}

C. Dumont, Christophe Levaillant, Mayeul Arminjon, J. Chenot. MODELLING OF DYNAMIC TENSION TESTS APPLIED TO DUCTILITY PROBLEMS. Journal de Physique Colloques, 1988, 49 (C3), pp.C3-505-C3-512. 10.1051/jphyscol:1988371 . jpa-00227794

\section{HAL Id: jpa-00227794 https://hal.science/jpa-00227794}

Submitted on 1 Jan 1988

HAL is a multi-disciplinary open access archive for the deposit and dissemination of scientific research documents, whether they are published or not. The documents may come from teaching and research institutions in France or abroad, or from public or private research centers.
L'archive ouverte pluridisciplinaire HAL, est destinée au dépôt et à la diffusion de documents scientifiques de niveau recherche, publiés ou non, émanant des établissements d'enseignement et de recherche français ou étrangers, des laboratoires publics ou privés. 
MODELLING OF DYNAMIC TENSION TESTS APPLIED TO DUCTILITY PROBLEMS

\author{
C. DUMONT, C. LEVAILLANT, M. ARMINJON and J.L. CHENOT \\ Ecole des Mines de Paris, Centre de Mise en Forme des Matériaux, \\ Sophia Antipolis, F-06565 Valbonne Cedex, France
}

\begin{abstract}
RESUME :
Nous proposons une simulation monodimensionnelle par éléments finıs de l'essai de traction dynamique. Nous mettons en évidence les conséquences d'une réduction locale de la section initiale de l'éprouvette et des effets d'inertie, en particulier sur l'histoire de la déformation et de la vitesse de déformation. L'influence des paramètres rhéologiques sur l'évolution de la ductilité est également étudiée.
\end{abstract}

\title{
ABSTRACT :
}

A one dimensional simulation of the dynamic tensile test, using the finite elements method is proposed. We enlighten the consequences of a local reduction of the initial specimen section and of inertia effects, in particular on strain and strain rate history. The influence of the rheological parameter on the ductility evolution has been also studied.

\section{INTRODUCTION}

Some forming processes as cold rolling, extrusion, fast machining lead to strain rates greater than $10^{3} \mathrm{~s}^{-1}$. For their understanding, it seems to be essential to determine the materials behaviour, in particular ductility and constitutive equations. The present work deals with the study of the rheological parameters influence on the metallic materials ductility. Several tensile tests $/ 1,2 /$ performed on a cross-bow tensile device developed at the CEA enable us to evidence a typical constitutive law at high rates of strain :

$$
\vec{\sigma}=\vec{\sigma}_{0}+\beta \dot{\bar{\varepsilon}} \quad \text { (1) with } \quad \bar{\sigma}_{0}=k \bar{\varepsilon}^{-n}
$$

Equation (1) can be justified on the basis of the viscous drag mechanism. In that case, the equation of a dislocation motion is

$$
\left(\sigma-\sigma_{0}\right) b=\bar{M} B v
$$

where $\sigma$ is the applied mechanical stress, $\sigma_{0}$ the threshold stress, $b$ the Burgers' vector, $B$ the drag coefficient, $v$ the dislocation velocity, $\vec{M}$ the average Taylor factor.

Combining equation (3) with Orowan's relation

$$
\dot{\bar{\varepsilon}}=\frac{1}{\bar{M}} \rho_{\mathrm{m}} \mathrm{b} \mathrm{v}
$$

where $\rho_{\mathrm{m}}$ is the mobile dislocation density, we get the linear constitutive equation

$$
\sigma=\sigma_{0}+\frac{\mathrm{BM}^{2}}{\rho_{\mathrm{m}} \mathrm{b}^{2}} \dot{\bar{\varepsilon}}
$$

If some research works refer to the linear law, complete studies concerning ductility under dynamic sollicitations are too scarce to deduce a general theory on the influence of rheological data on dynamic ductility. REGAZZONI /2, 3/ exhibited that inertial effects lead to a greater ductility. Considering a strained specimen with a lucal reduction of section, a finite difference method $/ 3 /$, shows an elastic unloading front. which propagates from the defect to the specimen ends whereas the plastic 
deformation develop until fracture in the necked part. These considerations involve an additional strain in the uniform region, called post-uniform elongation, which is negligible at low strain rates. Nevertheless, some other characteristics of each material may oppose themselves to this behaviour. Thus, KAWATA /4/ observes a decrease of ductility for body centered metals between static and dynamic strain rates (iron, molybdenum) and for some hexagonal close packed metals as zinc.

\section{NUMERICAL CALCULATIONS}

Our simulation uses a one dimensional finite element method. As GIANNOTTA /1/ exhibited the non-influence of radial inertia effects for the major test duration, we did not take it into account. Elasticity has been neglected, too. The problem is solved in terms of acceleration : the solution is found by an iterative NewtonRaphson algorithm, which makes the residue $R(\gamma)$ smaller than a specified tolerance, at each time increment. $R(\gamma)$ is obtained from the virtual rate of work equation :

$$
R(\gamma)=\int_{\Omega}[\sigma]:[\dot{\varepsilon}]^{*} d \omega+\int_{\Omega} \rho \gamma v^{*} d \omega=0
$$

where $[\sigma]$ is the stress tensor, $[\dot{\varepsilon}]^{*}$ the virtual strain rate tensor, $\gamma$ the accelaration, $v^{*}$ the virtual velocity and $\rho$ the density. $\Omega$ is representative of the studied solid.

The classical boundary condition for the node situated at the mobile head is empirically /1, 2/:

$$
v(t)=v_{M}\left[1-\exp \left(-\frac{t}{t_{c}}\right)\right]
$$

with $t_{C}=5 \mu \mathrm{s}$ and $V_{M}=L \dot{\varepsilon}_{0}$ (8), $V_{M}$ being the limit value of velocity, $L$ the specimen length and $\dot{\varepsilon}_{0}$ the nominal strain rate. We prefer the following equation to this law (7) :

$$
V(t)=\frac{V_{M}}{1+\left(\frac{t_{1}}{t}\right)^{3}}
$$

owing to numerical convergence considerations, equation 7 involving to a non zero value of acceleration at the initial time. The fixed number $t_{1}$ is adjusted in order to obtain the same maximal acceleration in equations 7 and 9 . The kinematical parameters $x, v$ and $\gamma$ at each new increment $t+\Delta t$ are calculated from a semi-implicit integration scheme. Thus :

$$
\begin{aligned}
& v=v_{0}+\frac{\Delta t}{2}\left(\gamma+\gamma_{0}\right) \\
& x=x_{0}+v_{0} \Delta t+\frac{\Delta t^{2}}{6}\left(\gamma+2 \gamma_{0}\right)
\end{aligned}
$$

$x_{0}, v_{0}$ and $\gamma_{0}$ being the coordinate, the velocity and the accelaration at increment $t$. The constitutive linear strain rate law is used in our computation (equation 1). The sample mesh is constituted by ten linear two nodes elements

\section{VALIDATION OF THE COMPUTATION}

Our simulation results were compared with experimental data, in particular with force-time recorded curves or with other computations.

\subsection{Load evolution}

Considering the stress $\sigma$ and the radius $\mathbf{r}$ of the extreme elements, we are able to obtain the load at the mobile head or at the fixed one : $F=\Pi r^{2} . \sigma(12)$. The parameters values for the constitutive equations are these indicated by GIANNOTTA for CUC1 copper at $20^{\circ} \mathrm{C}$ :

$$
k=650 \mathrm{MPa} \quad n=0,5 \quad \text { and } \beta=10^{-2} \mathrm{MPa} . \mathrm{s}
$$

The figure 1 gives us the comparison between our one dimensional computation and the experimental curve which is made up of two peaks. None are observed at the fixed head. The computation shows off an attenuated peak at the mobile head, but it 


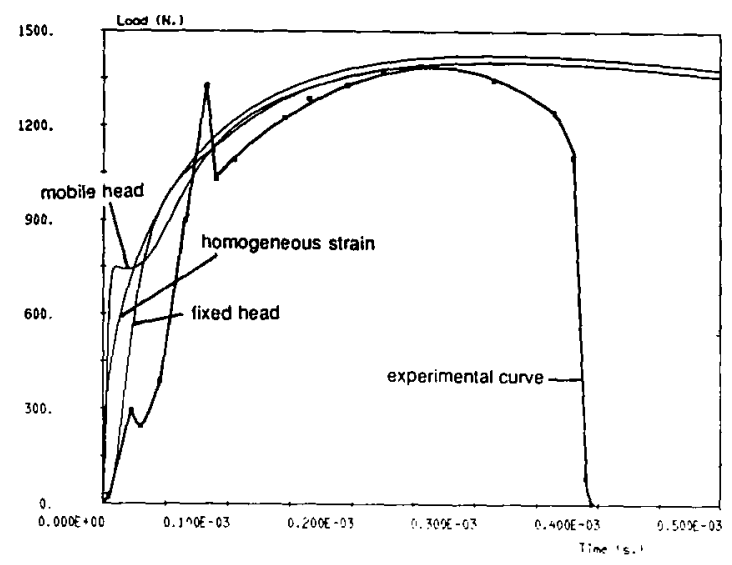

Figure 1 : Comparison between the experimental load versus time curve and computed ones at the mobile head and fixed head and with the assumption of homogeneous strain

appears at an earlier time than in experimental test. A two dimensional simulation $15 /$, using a modified version of the "FORGE $2 \mathrm{D}$ " code which consequently takes into account radial inertia effects, leads us to an analogous conclusion, and therefore to a more pronounced initial peak (fig. 2).

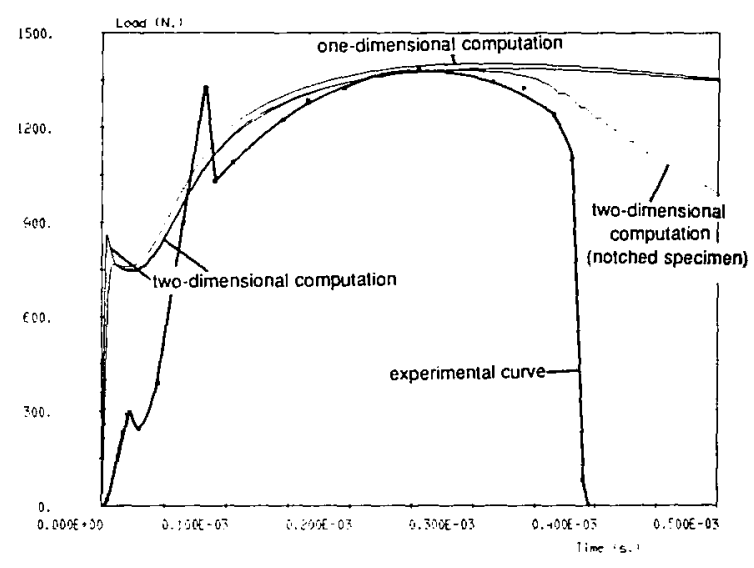

Figure 2 : Comparison between one and two dimensional computation, for evolution of load versus time

Beyond the first maximum and until the second maximum of the curves, all of them are in good agreement. After this stage, they diverge again, the experimental curve drapping down very rapidly. We also put on figure 1 , the evolution of the calculated load considering an homogeneous strain along the specimen, i.e. :

$$
\begin{aligned}
\dot{\varepsilon}(t) & =\dot{\varepsilon}_{0}=\frac{V_{M}}{L_{0}} \\
\text { Hence } \quad F(t) & =\left[K\left[\ln \left(1+\dot{\varepsilon}_{0} t\right)\right]^{n}+\beta \dot{\varepsilon}_{0}\right] \frac{\Pi r_{0}{ }^{2}}{1+\dot{\varepsilon}_{0} t}
\end{aligned}
$$

This curve varies in the same manner as the calculated ones. Thus, the maximum observed for experimental and computed curves is a direct consequence of the constitutive equation. The computation does not show a rapid decrease after the maximum, but it does not take into account damage effects. This can be done by using a two 
dimensional simulation of notched specimem. A $3 \%$ reduction of section in the middle of the sample leads to a rapid decrease of the load, much closer to the experimental curve.

\subsection{Evolution of strain rate and strain along the specimen}

Figure 3 shows inertia effects. In each element, the strain rate evolves with damped oscillations. The first maximum at the mobile head is very pronounced. As we move

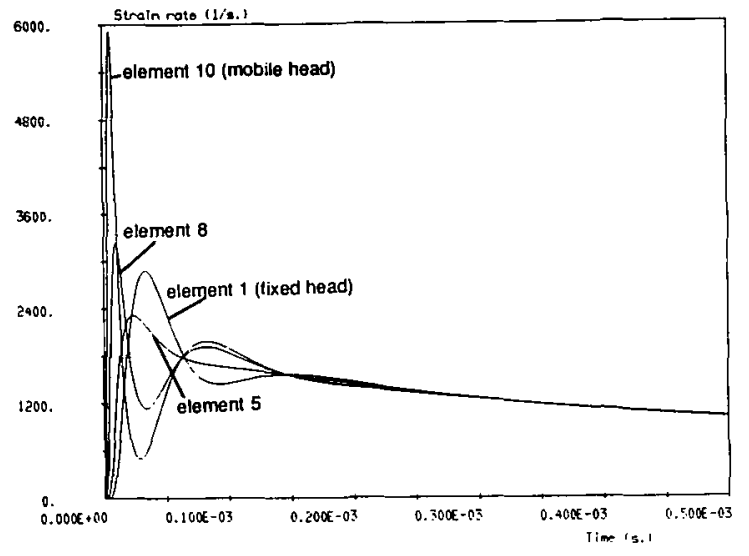

Figure 3 : Evolution of strain rate versus the time

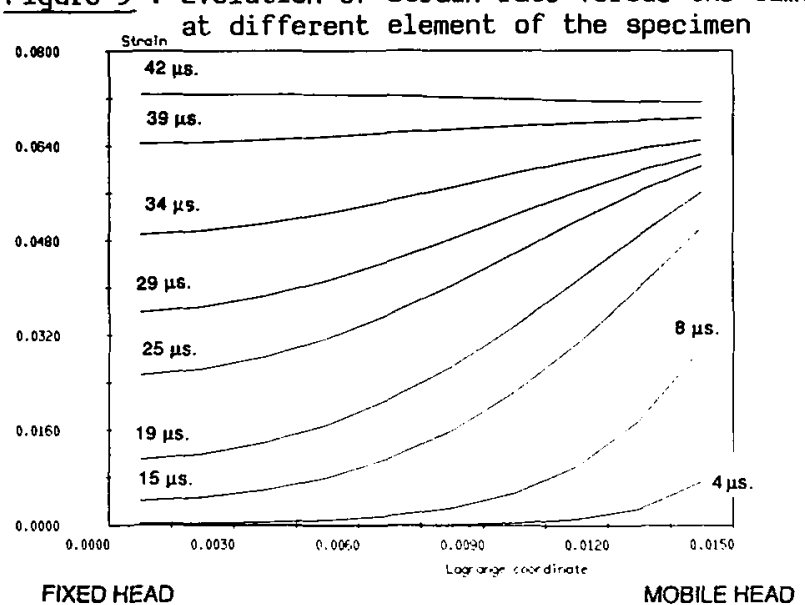

Figure 4 : Strain versus the Lagrange coordinate for different time increments

to the fixed head, its amplitude decreases and it appears a few microseconds later. We observe a first transient homogeneization of strain rate at $65 \mu s$ (node oscillation). It can be considered stabilized at about $140 \mu s$. Consequently, the strain along the specimen (versus the Lagrange coordinate) is concentrated at the mobile head at the early stage of the test as proved on figure 4. The strain at fixed head tends progressively towards the value at the mobile one. We observe a first homogeneization at $40 \mu \mathrm{s}$.

\subsection{Post uniform elongation}

In order to characterize more properly the dynamic elongation stability, the initial specimen geometry has been modified as in REGAZZONI's works /3/. Dynamic tensile calculations are performed on notched sample, consisting in a reduction of $1 \%$ of the fifth element radius value. After a first homogenization, the weak element is 


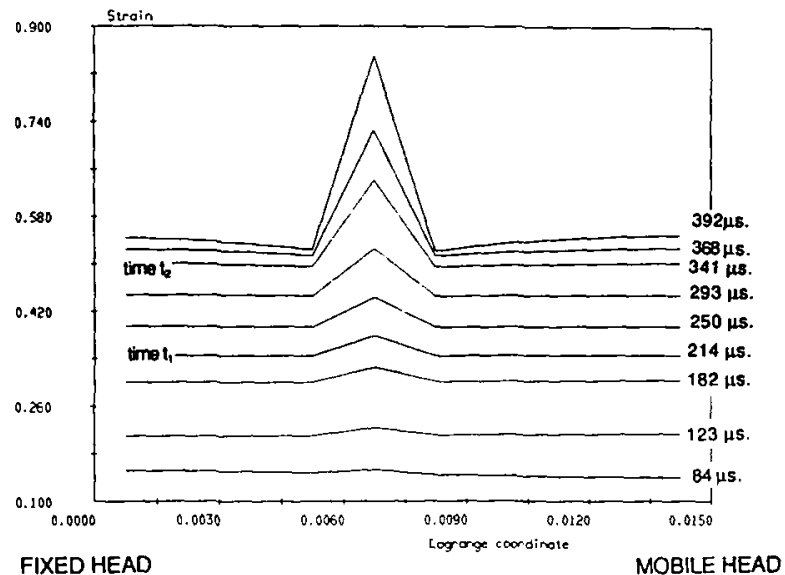

Figure 5 : Evolution of strain along the specimen at different time increment for a notched specimen

strained more rapidly than the others. As notified in REGAZZONI's research, dur 1 ng the second stage, the strain in the homogeneous part decreases progressively but is not negligible. We assume the following definition : post-uniform elongation is the strain of the homogeneous part of the specimen between two particular moments $t_{1}$ and $t_{2}$ corresponding to increments number $n_{1}$ and $n_{2}$ as :

Variation of the radius of the weakened element between increments $n_{1}-1$ and $n_{1}>1,2$ Variation of the mean radius of the other elements between increments $n_{1}-1$ and

n!

Variation of the mean radius of the homogeneous part elements between increments $n_{2}-1$ and $n_{2}$

Variation of the mean radius of the homogeneous part elements between $>1,1$ increments $n_{2}$ and $n_{2}+1$

The post-uniform deformation varies linearly with strain rate between $250 \mathrm{~s}^{-1}$, in agreement with REGAZZONI's results. Beyond this strain rate range, it seems that post-uniform elongation evolution is more complex.

\section{INFLUENCE OF TEST CONDITIONS}

\subsection{Influence of the defect position}

The defect position has not a great influence on dynamic tensile elongation. When we modify the defect site along the specimen, the evolution of strain and post-uniform deformation (Table $I$ ) is quite similar in all the cases, except at the mobile head where the neck sfarts to propagate earlier : moment $t_{1}$ is equal to $80 \mu s$ against $220 \mu \mathrm{s}$ at $2000 \mathrm{~s}^{-1}$ in the other situations.

Table I : Value of post-uniform deformation for different defect positions

\begin{tabular}{|c|c|c|c|c|}
\hline defect position & Element 2 & Element 5 & Element 8 & $\begin{array}{c}\text { Element 10 } \\
\text { mobile head }\end{array}$ \\
\hline Past-uniform deformation \% & 15,5 & 15,4 & 13 & 37,8 \\
\hline
\end{tabular}

\subsection{Influence of strain rate}

A non-linear post-uniform elongation versus strain rate has been observed beyond $2000 \mathrm{~s}^{-1}$. The following results (Table II), were obtained for a defect located on the fifth element. 
Table II : Value of post-uniform deformation for different strain rates

\begin{tabular}{|l|c|c|c|c|c|c|c|c|}
\hline Nominal strain rate $\mathrm{s}^{-1}$ & 3000 & 4000 & 5000 & 6000 & 7000 & 8000 & 9000 & 10000 \\
\hline Post-uniform deformation $\%$ & 16,3 & 18,8 & 21,8 & 27,1 & 27,3 & 24,5 & 16 & 0,07 \\
\hline
\end{tabular}

Post-uniform deformation increases up to $6000 \mathrm{~s}^{-1}$, passes through a maximum and decreases to a nearly zero value at $10000 \mathrm{~s}^{-1}$. At this'strain rate, the moments $t_{1}$ and $t_{2}$ appear early and are near from each other $\left(t_{1}=92 \mu \mathrm{s}\right.$ and $\left.t_{2}=109 \mu \mathrm{s}\right)$. At such high strain rates, in spite of the weakened element at the middle of the specimen, strain concentrates at the mobile head.

Taking this remark into account, the same study has been undertaken with the reduction of section located at the mobile head. In that case, post-uniform deformation decreases as soon as $2000 \mathrm{~s}^{-1}$.

Table III : Value of post-uniform deformation for different strain rates

\begin{tabular}{|l|c|c|c|c|c|c|c|}
\hline Nominal strain rate $\mathrm{s}^{-1}$ & 2000 & 3000 & 4000 & 5000 & 6000 & 9000 & 10000 \\
\hline Post-uniform deformation $\%$ & 37,8 & 26,9 & 21,6 & 16,2 & 15,9 & 15 & 14,7 \\
\hline
\end{tabular}

Therefore, the strain localized at the mobile head leads to a decrease of post uniform deformation versus strain rate. Consequently, ductility evolves in the same manner for very high strain rates (up to $6000 \mathrm{~s}^{-1}$ ) wherever the defect position or for the defect at the mobile head whatever the strain rate.

\section{INFLUENCE OF RHEOLOGICAL PARAMETERS AND MATERIAL DENSITY}

Many computations have been performed from different rheological parameters and material density values, varying in a range deduced from the literature. So the following parameters were used : $\rho=2700 \mathrm{~kg} / \mathrm{m}^{3}, 8920 \mathrm{~kg} / \mathrm{m}^{3}, 16600 \mathrm{~kg} / \mathrm{m}^{3} ; \beta=10^{-1}$ MPa.s, $10^{-2} \mathrm{MPa} . \mathrm{s}, 10^{-3} \mathrm{MPa} . \mathrm{s} ; \mathrm{K}=200 \mathrm{MPa}, 1000 \mathrm{MPa} ; \mathrm{n}=0.2,0.5$.

Ductility evolution was characterized by post-uniform elongation and by the area reduction coefficient $Z$, with :

$$
Z=\frac{S(t)-S_{0}}{S_{0}}=1-\frac{r^{2}(t)}{r_{0}^{2}}
$$

where $S(t)$ and $r(t)$ are the section and the radius of the weakened element at the time $t, S_{0}$ and $r_{0}$ the initial section and the initial radius of the weakened element. Computation results are partially presented on figure 6 and tables IV and V.

Table IV : Value of post-uniform elongation with $K=1000 \mathrm{MPa}$ and $\mathbf{n}=0.5$

\begin{tabular}{|c|c|c|}
\hline$\rho \mathrm{kg} / \mathrm{m}^{3}$ & $10^{-2}$ & $10^{-1}$ \\
\hline 2700 & 15,3 & 24,1 \\
\hline 8920 & 14,6 & 26,9 \\
\hline 16600 & 13,5 & 26,9 \\
\hline
\end{tabular}

Table $V$ : Value of post-uniform elongation with $\beta=10^{-2} \mathrm{MPa}$ and $\mathrm{n}=0.5$

\begin{tabular}{|c|c|c|}
\hline$\rho \mathrm{kg} / \mathrm{m}^{3} \mathrm{~K} \mathrm{MPa}$ & 200 & 1000 \\
\hline 2700 & 21,6 & 15,3 \\
\hline 8920 & 24,1 & 14,6 \\
\hline 16600 & 24,3 & 13,5 \\
\hline
\end{tabular}




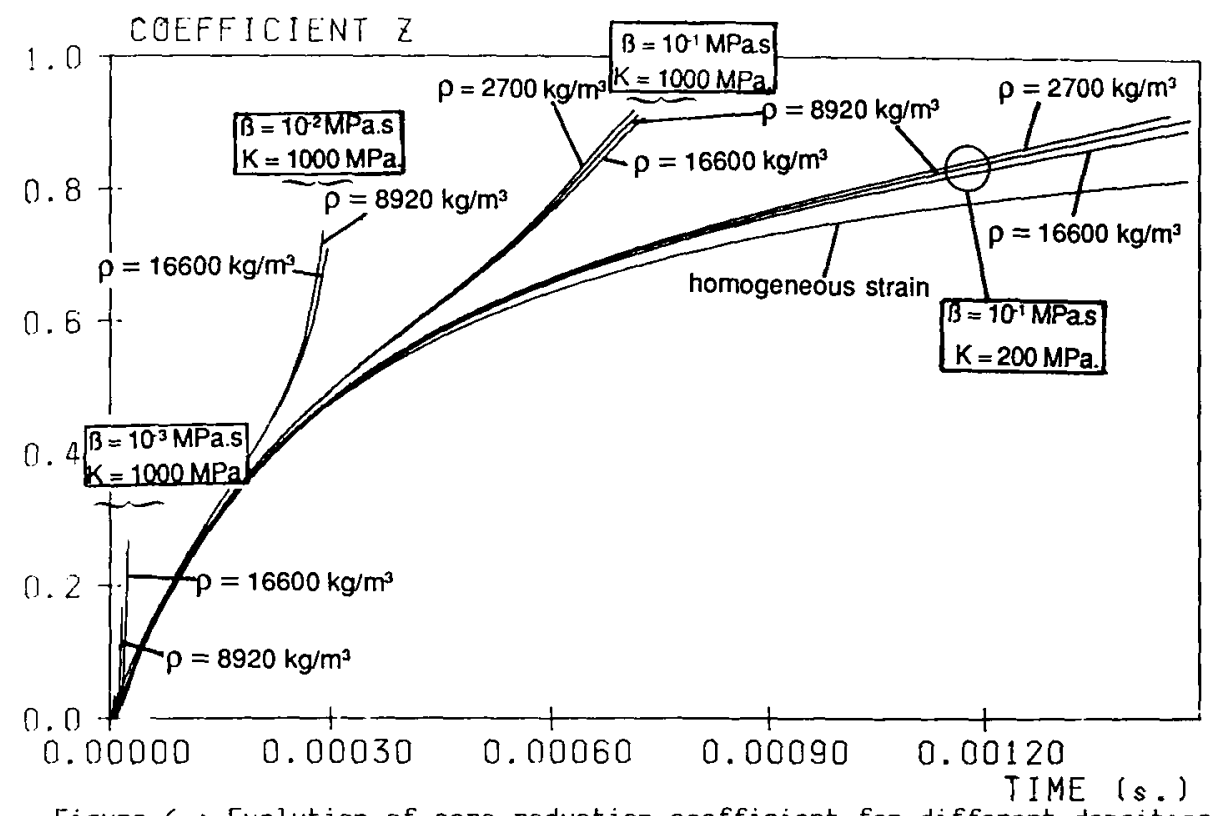

Figure 6 : Evolution of aera reduction coefficient for different densities $p$ and $\beta$ coefficients with $K=1000 \mathrm{MPa}$ or $K=200 \mathrm{MPa}, n=0.5$ at $\dot{\varepsilon}_{0}=3000 \mathrm{~s}^{\mathrm{I}}$

The area reduction coefficient $z$ is particularly sensitive to the rheological parameters $\beta$ and $K$. Thus, a high value of $\beta\left(\beta=10^{-1} \mathrm{MPa} . \mathrm{s}\right)$, and a small one for $k$ lead to optima conditions $i . e$. to the highest post-uniform elongation and to the slowest increase of parameter $Z$. On the other hand, the density and the coefficient $n$ have not a great influence in spite of a non negligible relation between density and inertia effects. Nevertheless, a high value of hardening coefficient $n$ and of density are favourable to ductility evolution in dynamic conditions. The ideal conditions are obtained with :

$$
\rho=16600 \mathrm{~kg} / \mathrm{m}^{3}, \quad K=200 \mathrm{MPa}, \quad n=0,5 \text { and } \beta=10^{-1} \mathrm{MPa} . \mathrm{s}
$$

They do not correspond to an actual material but to a combination of parameters reported on various materials. In that case, the evolution of parameter $Z$ is in good agreement with the one calculated in the assumption of homageneous strain :

$$
Z=1-\frac{r^{2}}{r_{0}{ }^{2}}=\frac{\dot{\varepsilon}_{0} t}{1+\dot{\varepsilon}_{0} t}
$$

So the strain in the necked element increases slowly and remains of the same order as the one in the other elements. We plotted on figure 7 , the evolution of strain rate sensivity parameter :

$$
m=\frac{\partial \ln \sigma}{\partial \ln \dot{\varepsilon}}=\frac{\beta \dot{\varepsilon}}{K \varepsilon^{n}+\beta \dot{\varepsilon}}
$$

versus the specimen elongation : $m$ reaches high values, especially at the early stage of the test, where it is nearly equal to one, as in the case of a superplastic material. Meanwhile, the considered strain rate scale and the micromechanism implied, are very evidently quite different. The curve remains widely over the one calculated with the rheological parameters of CuC1 at $20^{\circ} \mathrm{C}$.

The force at the mobile head leads us to the same conclusion. The curve presents the same characteristics than the load evolution of a superplastic material : after a very pronounced initial peak, we observe an hyperbolic decrease (figure 7 ). 


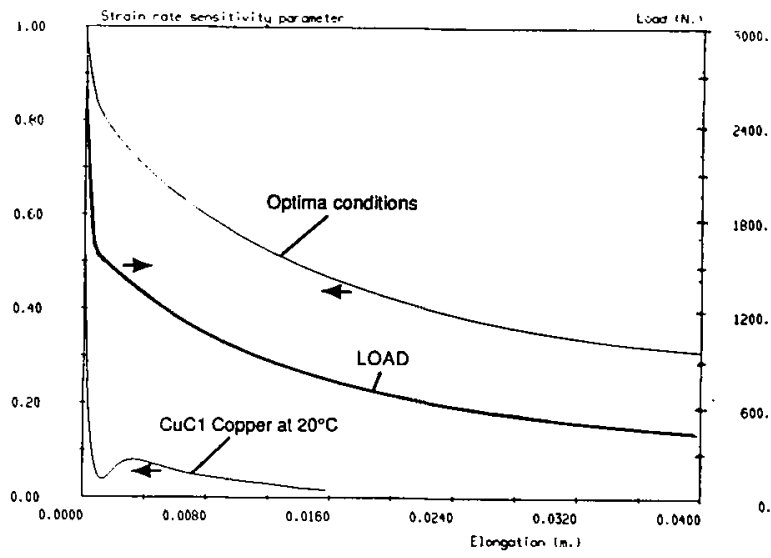

Figure 7 : Evolution of the strain rate sensitivity parameter and of the load versus elongation at $3000 \mathbf{s}^{-1}$ (mobile head)

\section{CONCLUSION}

The computation code developed in this study enables us to understand the development of the dynamic tensile test, particularly the complex story of strain rate and strain in the specimen. As in REGAZZONI's, post-uniform deformation has been enlightened which enables us to justify the ductility increase measured on face centered cubic materials, between quasistatic and dynamic strain rates. In spite of inertia effects, the growth of the necked part of the specimen is not influenced by its position along the sample, except at the mobile head. In that case, post-uniform deformation decreases versus the strain rate, whereas it is always increasing up to $6000 \mathrm{~s}^{-1}$ for the other situations.

A small value of the coefficient $K$ and a high one for $\beta$ lead to high values of the strain rate sensitivity parameter, and consequently lead to a behaviour analogous to a superplastic material, but for a high strain rate range. A high density is favourable owing to inertia effects, but its influence is negligible in comparison with rheological parameters.

Nevertheless, this computation cannot be dissociated from experimental results. Other parameters, characteristic of each materials (cristallographic structure, micromechanism of strain), which are not taken into account in these calculations may have opposite effects. On the other hand, improvements of the method can be done, in particular by taking into consideration thermal effects.

\section{REFERENCES}

11/ J.C. GIANnotTA, "Comportement mécanique et évolution structurale de cuivres de haute pureté dans le domaine dynamique", Thèse de Docteur en Sciences et Génie des matériaux, Ecole Nationale Supérieure des Mines de Paris (1986)

/2/ G. REGAZZONI, "Comportement et ductilité du cuivre et du tantale purs dans le

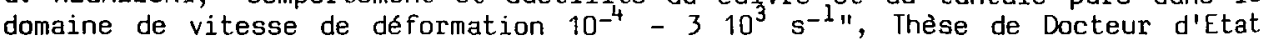
es-Sciences, Université de Grenoble (1983)

/3/ G. Regazzoni, J.M. JOHnSDn, P.5. FOLLAnSBEe, J. of Appl. Mech., 53, 519 (1986)

14/ K. KAWATA, 5. HASHIMOTO, K. KUROKAWA, "High Velocity Deformation of Solids", Eds. K. Kawata et J. Shiori, Springer Verlag, New-York, 1, (1978)

15/ M. ARMINJON, J.L. CHENOT, Int. Num. Methods Eng. : Theory and Applications, Eds. G.N. Pane et J. Middleton, Martinus Nijhoff publishers, Swansea, 2, 1-10 (1987) 